\title{
Ética organizacional e Relações Públicas
}

\section{Mario Ernesto Humberg}

- Bacharel e Licenciado em Química pela Universidade de São Paulo (USP)

- Autor do livro Ética na política e na empresa

- Ex-presidente da Associação Brasileira de Empresas de Comunicação e Relações Públicas (Abert)

- Jornalista profissional, foi diretor das editoras Abril, Sorel, Noticiário da Moda, Gazeta Mercantil e CL-A Cultural

- Consultor de comunicação e ética organizacional

- Presidente da CL-A Comunicações, empresa full-service de Relações Públicas, fundada em 1980

- Coordenador do Pensamento Nacional das Bases Empresariais (PNBE)

- Presidente do Instituto PNBE de Desenvolvimento Social

- Conselheiro da Fundação Padre Anchieta (Rádio e TV Cultura)

- marioernesto.humberg@cl-a.com 
Analisa a evolução da ética empresarial e organizacional no mundo, seus problemas no Brasil, bem como os principais aspectos dos programas de ética em relação aos empregados no Brasil, os novos desafios para a implantação de programas e outros aspectos. Comenta quem atua no setor e suas características e os pontos de desencontro com a atividade de Relações Públicas.

PALAVRAS-CHAVE: ÉTICA ORGANIZACIONAL • ÉTICA EMPRESARIAL • RELAÇÕES PÚBLICAS • COMUNICAÇÃO ORGANI-

ZACIONAL • CÓDIGO DE CONDUTA • CÓDIGO DE ÉTICA

Abstract

It analyzes the evolution of Business Ethics, its problems in Brazil, the difficulties and principal aspects of the ethics programs in relation to employees in Brazil, as well as the challenges for implementation of programs and other aspects. It also comments on the different origins of the professionals of the sector and the points of conflict with public relations activities.

KEYWORDS: BUSINESS ETHICS • PUBLIC RELATIONS • ORGANIZATIONAL COMMUNICATION • BEHAVIOR CODE • CODE

OF ETHICS

\section{Resumen}

Se analiza la evolución de la ética de negocios y sus problemas en Brasil; especialmente, las dificultades con relación a los empleados, así como las tendencias y los retos para el futuro. También se comentan las diferentes características de los profesionales que actúan en el sector y los puntos de desencuentro con la actividad de Relaciones Públicas.

PALABRAS CLAVE: ÉTICA ORGANIZACIONAL • ÉTICA EMPRESARIAL • RELACIONES PÚBLICAS • COMUNICACIÓN ORGANIZACIONAL • CÓDIGO DE CONDUCTA • CÓDIGO DE ÉTICA 


\section{Ética Empresarial no Brasil e no mundo}

$E_{\text {tic }}$ tica Empresarial passou a ser um tema presente nas apresentações, relatórios e projetos das empresas apenas recentemente no Brasil, seguindo uma tendência delineada nos Estados Unidos a partir do final da década de 1970. Em palestra realizada em São Paulo, em 1997, Thomas Donaldson, professor de Business Ethics na Wharton School da Pennsylvania University, mostrou a grande evolução ocorrida no setor acadêmico de seu país, a partir daquela década. Segundo ele, 20 anos antes havia nos Estados Unidos apenas três livros sobre Ética Empresarial, e nas faculdades quase não existiam aulas sobre o tema. Em 1997, em todas as mais de 7.000 faculdades do país já havia cursos a respeito, sendo que $90 \%$ dos alunos de Administração freqüentavam a cadeira (HUMBERG, p. 59). Nessa época, no Brasil, praticamente só existia a cadeira de Ética Empresarial na Fundação Getúlio Vargas, em São Paulo.

Apesar de recente, tanto do ponto de vista acadêmico como do ponto de vista das empresas, a Ética Empresarial (ou Organizacional, ou, ainda, Ética nos Negócios) evoluiu muito rapidamente entre nós. Hoje todas (ou quase todas) as faculdades de Administração reservam-lhe uma cadeira e muitos outros segmentos universitários e mesmo escolas secundárias a implantaram.

Essa grande evolução ao longo dos últimos trinta anos teve seu primeiro impulso nos Estados Unidos, com o chamado Escândalo Lockheed, a descoberta de que várias empresas do setor de equipamentos militares, entre os quais a que deu nome ao processo, subornavam autoridades de outros países para obter contratos. A divulgação da existência desse sistema de corrupção, que incluía até o marido da rainha da Holanda, levou a uma desconfiança geral em relação ao procedimento empresarial.

Como reação à insatisfação social gerada nos Estados Unidos, o governo criou o FCPA (Foreign Corruption Practices Act), que estabelece sanções pesadas para a prática de atos de corrupção no exterior, e as empresas passaram a estabelecer normas mais claras sobre seus modos de agir. Isto foi feito com a implantação de Códigos de Conduta ou Códigos de Ética e de programas para sua divulgação e auditoria, uma vez que já se havia definido como Ética Empresarial o conjunto de formas de proceder das empresas em relação aos seus públicos (stakeholders). Como diz um dos líderes da ISBEE (International Society of Business, Economics, and Ethics), Georges Enderle ${ }^{1}$, professor de International Business Ethics da University of Notre Dame: "Business ethics se refere a todas as atividades dos negócios e às regras que orientam os negócios... ética da concorrência, (ética) da inovação, (ética) financeira, (ética) do marketing etc. Todos são aspectos importantes da responsabilidade corporativa". ${ }^{2}$ Com base no conceito de Ética Empresarial, passou-se também a falar em Ética Organizacional para se referir a todas as organizações e não apenas às empresas.

1 http://www.nd.edu/ genderle/

2 Citação traduzida pelo autor. 
Antes dos Códigos de Ética, as empresas e organizações se pautavam pelos valores e crenças de seus fundadores e donos, transformados em normas que, na maior parte das vezes, não constituíam uma declaração escrita; muitas vezes eram traduzidas em frases curtas e, em alguns poucos casos, explicitadas por meio de documentos mais abrangentes. Os principais aspectos dessas normas antigas se referiam às relações com os empregados ou funcionários - quase sempre impondo restrições - e aos clientes, que a empresa deveria buscar atender da melhor forma para garantir sua fidelidade. A relação com outros stakeholders - governos, comunidade próxima, fornecedores, concorrentes e mídia raramente eram objeto de normas. Quanto aos acionistas, quando a organização era de propriedade coletiva, existiam acordos entre eles, geralmente fora do conhecimento de terceiros.

Recentemente, no final do milênio anterior e início deste, grande impulso foi dado à implantação de programas e Códigos de Ética, após a série de escândalos envolvendo as ligações de grandes empresas e políticos em países europeus, como França, Itália e Alemanha, além de Coréia e Japão. Nos Estados Unidos, houve a quebra fraudulenta de grandes empresas, em 2002, das quais a Enron e a Arthur Andersen ficaram como símbolos. Em reação, o congresso norte-americano aprovou a chamada Lei SarbanesOxley (Sarbox), que criou novas exigências de transparência, ao lado de responsabilidades adicionais dos administradores e conselheiros. As empresas de capital aberto (public companies) passaram a ser obrigadas a ter um Código de Ética e sistemas de auditoria, o que se refletiu no Brasil, onde as principais companhias atuantes na Bovespa também negociam seus papéis na Bolsa de Nova Iorque (NYSE).

Assim, nos últimos anos, Códigos de Ética ou de Conduta, formulados de forma mais abrangente e divulgados interna e externamente, foram implantados por muitas empresas no Brasil, e se incorporaram à Governança Corporativa, processo de melhoria da gestão e transparência das empresas, iniciado pelas companhias de capital aberto.

Hoje, há uma tendência geral das empresas, de outras organizações e mesmo de áreas governamentais para melhorar o que existe de normas internas e procedimentos externos, para preparar Códigos e divulgar esses documentos, por várias motivações.

Vários autores chamam a atenção para a correta motivação da implantação do Código de Ética, como é o caso de uma das maiores especialistas brasileiras, a professora Maria Cecília Coutinho de Arruda, da Fundação Getúlio Vargas (FGV-SP) e também membro do Comitê Executivo da ISBEE e das organizações brasileiras e latino-americanas do setor. Diz ela: "este livro trata da visão positiva de se criar um Código de Ética que acrescenta valor à instituição, sem a preocupação apenas mercadológica de satisfazer clientes ou fortalecer a imagem da organização para fins externos ou de relações públicas." (ARRUDA, p. 1)

Não que Cecília Arruda despreze esses efeitos, mas tanto ela como outros importantes autores consideram que esse deve ser um dos resultados, e não a motivação para implantar o Código de Ética. Ao avaliar vários Códigos de Ética, de empresas e de entidades, incluídos no livro, Arruda (p. 26) considerou que sua motivação foi adequada e concluiu que "predomina, assim, o caráter construtivo". 


\section{Dificuldades para implantar programas de ética no Brasil}

A implantação de um programa de ética abrangente implica em mudanças muito significativas na forma de proceder da organização. O Código de Ética é uma declaração de princípios e, ao mesmo tempo, um estatuto ou constituição a que todos se obrigam, a começar da cúpula, o que exige o envolvimento e a participação geral, desde a presidência e a diretoria, para se tornar efetivo. É diferente das antigas normas de procedimento definidas pela empresa, que estabeleciam apenas o que os empregados podiam, ou não, fazer, e criavam sanções e restrições, e que muitas vezes também eram chamados de Código de Conduta ou até de Código de Ética.

Assim, no início da formação das empresas, sua ética (ou, de modo mais simples, seu comportamento) era definido pela interação entre os valores aceitos pela sociedade e os dos donos. Os diferentes impactos das mudanças sociais ocorridas nos últimos séculos, como o crescimento do sindicalismo, a multiplicação das ONGs - organizações não-governamentais -, a preocupação com o meio ambiente, a qualidade de vida e outras foram assumidos nos Códigos de Ética iniciais. Contestações internas e externas vêm levando ao aperfeiçoamento desses documentos e à criação de verdadeiros programas de ética que obrigam a organização e envolvem todos os stakeholders.

Como os pontos de partida para os programas de ética eram os valores da sociedade e dos donos das empresas, a questão no Brasil tem aí sua primeira dificuldade. As bases do que se chama comportamento ético, ou simplesmente ética, são valores como a integridade pessoal, a boa-fé, o respeito pelos outros e pelo bem comum. Enquanto a integridade e a boa-fé parecem ter deixado de ser valores para uma parte significativa das lideranças e da população brasileira, o respeito pelos outros e pelo bem comum é algo muito recente no país e ainda não consolidado. Basta lembrar que saímos do regime escravagista há apenas 120 anos e muitas seqüelas desse tempo são ainda componentes da forma de agir das classes mais privilegiadas.

Pode-se inclusive dizer que na maior parte da área empresarial (há exceções - e muitas, infelizmente), a situação em relação a esses aspectos é melhor do que no geral da sociedade, em função da própria necessidade que tem a empresa de gerar confiança interna. "Uma das grandes questões da liderança (empresarial) contemporânea é a integridade. Ela é necessária para que o líder consiga infundir segurança entre os liderados. Ele tem de ser confiável”, afirma Warren Bennis, fundador do Leadership Institute da University of Southern Califórnia (depoimento a Ângela Pimenta, Revista Exame, 18/08/2004, p. 47).

O respeito pelos outros, para ser uma base da ética da empresa, precisa ser uma postura abrangente da empresa ou organização, incluindo todos aqueles que com ela se relacionam, direta e indiretamente (stakeholders): empregados, clientes e consumidores, acionistas, fornecedores e financiadores, governos e seus agentes e órgãos, comunidade próxima, organizações não-governamentais, lideranças sociais e sociedade em geral - o que em Relações Públicas se denomina como os públicos da empresa. 
No entanto, as primeiras pesquisas conduzidas no país sobre Ética Empresarial, na década de 1980, por entidades como a Fundação Fides (1982), apresentaram um panorama pouco animador: a maior parte das empresas preferia não responder às pesquisas, ou, quando o fazia, mostrava lacunas em quase todos os seus relacionamentos. Não é de se estranhar, num país em que a esperteza é considerada um valor, os políticos, governantes e a burocracia criam dificuldades para vender facilidades e a sociedade aceita esse comportamento. Trata-se de uma distorção que tem raízes históricas e que se repete ao longo dos séculos, apesar das constantes denúncias. Roberto Teixeira da Costa, dirigente empresarial que foi responsável pela implantação da CVM (Comissão de Valores Mobiliários), órgão de regulação do mercado de capitais, e que participou da elaboração da reforma da Lei das S / A, em 1976, lembra que o artigo 154 já estipulava que "o administrador [da empresa] deve exercer as atribuições que a Lei e o Estatuto lhe conferem para lograr os fins no interesse da companhia, satisfeitas as exigências do bem público e a função social da empresa" (grifos do autor). No que se refere aos políticos, ele anotava, em 1992:

"O momento político que vive o Brasil tem sido marcado por uma grande riqueza de fatos que estão vindo a público e que, se devidamente analisados, poderão servir para uma importante mudança de hábitos e costumes que foram aceitos por nossa sociedade como 'normais' ao longo do tempo" (TEIXEIRA DA COSTA, 2006).

Infelizmente, os fatos continuam a ser considerados "normais" ou se enquadram em uma das "leis" que se tornaram padrão de comportamento para muitos, particularmente dos políticos:

- Lei do mais forte - quem pode manda, e quem tem juízo obedece

- Lei de Gerson - é preciso levar vantagem em tudo

- Lei de Robertão ou dos políticos - é dando que se recebe

- Lei dos espertos - se os outros podem e fazem, por que nós não?

- Lei dos marxistas e outros - os fins justificam os meios

Ao lado dessas "leis", fortemente arraigadas na maior parte das lideranças políticas e em outros segmentos sociais, existe uma forte tendência àquilo que eu costumo chamar de flexibilidade ética: aceitamos conviver e até aplaudir pessoas cujo comportamento foge à ética e, muitas vezes, é até claramente passível de enquadramento como crime.

Esses aspectos dificultam especialmente a definição dos procedimentos da organização em relação a dois grupos de seus stakeholders: os funcionários ou empregados, e os ocupantes de cargos públicos, políticos ou assemelhados. Pela limitação do espaço do artigo, detenho-me à abordagem apenas em relação ao primeiro grupo, que hoje recebe também outros nomes: colaboradores, integrantes, liderados e outros termos.

\section{0 relacionamento com os empregados}

As relações de trabalho só começaram a ser reguladas no Brasil com respeito aos empregados a partir de 1925, 37 anos após o fim da escravidão, quando foi pela primeira vez regulamentado o direito a férias - 15 dias anuais. Mas, até a chegada da CLT, a 
situação dos trabalhadores era de total falta de garantias no trabalho e de direitos não havia preocupação com segurança, condições de trabalho, idade mínima, jornada diária, direitos da gestante e da mãe, entre outros.

Nesse ambiente de exploração do trabalhador, houve alguns casos significativos de aplicação de valores éticos no relacionamento com empregados que hoje são citados como exemplos, entre os quais os de Luiz Tarquínio, na Bahia, Delmiro Gouveia, em Pernambuco e Jorge Street, em São Paulo.

Luiz Tarquínio, filho de uma ex-escrava, fundou, em 1891, em Salvador, a Companhia Empório Industrial do Norte, que se tornou uma das maiores tecelagens do Brasil. A empresa já teve início com o que era na época a maior vila operária do país, com 258 casas, além de toda a infra-estrutura de educação, cultura, lazer e de serviços. Ele costumava dizer que "a necessidade de normas morais é tão antiga quanto a vida social e que a moral não possui sua origem fora do homem, e sim no homem que sente, pensa, transforma e constrói” (DUMÊT; TARQUÍNIO, p. 18). Sua visão dos direitos do trabalho e do trabalhador foi a base para construir a vila operária, apenas três anos depois da libertação dos escravos, mas o tempo mostrou que essa iniciativa também trazia retorno financeiro: enquanto a média de faltas ao trabalho era de $15 \%$ nas outras fábricas, na sua não chegava a 1\% (DUMÊT; TARQUÍNIO, p. 19). Comportamento similar teve em São Paulo, no início do século, o empresário, também do setor têxtil, Jorge Street, que oferecia boas condições de trabalho aos empregados e criou para eles a Vila Maria Zélia, hoje tombada. Mas enquanto a obra de Tarquínio não resistiu ao seu desaparecimento, a de Street ruiu com ele ainda vivo, mostrando que esse procedimento empresarial não tinha muito sucesso à época.

Jacques Marcovitch, em seu livro Pioneiros e empreendedores, traz vários exemplos dessa visão social, geralmente somada ao autoritarismo e ao paternalismo, no início dos anos 1900. Um deles é o de Delmiro Gouveia (p. 150 e ss.), um empresário lendário no Nordeste, objeto de cordéis, músicas e outras manifestações populares. Sua fábrica de linhas em Pedra, AL, inaugurada em 1913, contava com moderna vila operária e oferecia excelentes condições aos moradores, mas era-se obrigado a viver dentro das regras e regulamentos que Delmiro criara, tanto na fábrica como na vila. "Aos recém-chegados Delmiro costumava alertar que em Pedra ele era tudo: Deus, o diabo, a mais alta autoridade" (apud LIMA JUNIOR, 1963). Outro exemplo é o das Casas Pernambucanas e de Frederico Lundgren, (MARCOVITCH, vol. 3, p. 46), com o depoimento de um ex-contramestre, sobre a introdução das leis trabalhistas:

"Naquele tempo era fácil encontrar trabalho na fábrica ${ }^{3}$ não precisava de documentos nem nada. Havia muita folga no trabalho, e às vezes trabalhavam dez pessoas num lu-

30 grupo fundado por Herman Lundgren e dirigido por seus filhos Frederico e Arthur, a partir de 1907, era dono da Fábrica de Tecidos Paulista, no município de Paulista, PE, e, em 1924, inaugurou a fábrica Rio Tinto, em Mamanguape, PB. Ambas contavam com vilas operárias de bom padrão, que chegaram a ter seis mil e três mil casas, respectivamente (em 1950), além de contarem com ferrovia, cerâmica, porto, usina, serviços de água e energia próprios, clínica, teatro, escolas, igreja, clube etc. (MARCOVITCH, vol. 3, p. 42). Para vigiar os $241 \mathrm{~km}$ de terras de propriedade do grupo em Paulista, chegou-se a ter 743 homens, que controlavam o comportamento dos operários e de suas famílias. 
gar onde bastava uma. Mas quando vieram as leis, ai começaram a exigir documentose a não admitir operários tão facilmente e a cortar salários. O coronel Frederico era bom, mas ele queria fazer a bondade dele, ele não queria que outro viesse e dissesse: 'Dê isso a esse rapaz'. Ai ele resistiu às leis, evidentemente." (apud ALVIM, 1977)

A situação evoluiu, mas, mesmo no pós-guerra, e até recentemente, era comum a existência de empresas onde não se admitiam negros, pessoas com barba, com deficiências, mulheres ou outros grupos. Evidentemente essa situação vem mudando de forma constante, num processo que teve como marcos a criação da legislação trabalhista, em 1937, o fortalecimento das organizações sindicais, a crescente fiscalização dos governos, da mídia e da sociedade. Assim, nos principais centros, hoje, os direitos básicos dos trabalhadores são respeitados, mas, mesmo nas grandes cidades, continuam a existir abusos. E iniciativas com as de Luiz Tarquínio, em 1891, de buscar condições dignas para todos que trabalhavam em sua empresa, ainda não são comuns - trabalhadores de muitas grandes empresas não contam com habitações e outras condições de vida adequadas.

Do ponto de vista da ética empresarial, também não existe ainda, de modo mais amplo, um verdadeiro respeito ao trabalhador menos qualificado, que raramente é ouvido e em muitos lugares permanece sujeito àquilo que hoje se caracteriza como assédio moral.

"Todos os empregados - e não apenas quem carrega uma pastinha-devem ser ouvidos. Os funcionários da fábrica precisam saber que são mais do que um par de mãos e uma simples engrenagem para a empresa. Suas idéias contam. Por isso é preciso ouvi-los tanto em fóruns organizados, onde os trabalhadores são encorajados a discutir formas de melhorar as operações da companhia, como informalmente, passeando pelo chão de fábrica." (Jack Welch com Suzy Welch em Exame, 14.02.07, p. 98/99)

Os programas de ética estimulam os colaboradores e aumentam sua eficácia operacional, pois, com o aumento da transparência, o foco passa a ser a realização de bons negócios por toda a equipe, que acompanha os resultados reais.

Assim, a implantação de um programa de ética na empresa deve começar ouvindo todos seus empregados sobre o que eles consideram como os valores efetivamente existentes na empresa, quais eles vêem como positivos e quais eles sugerem sejam alterados. A partir daí se pode elaborar um pré-Código, para ser discutido e melhorado em várias instâncias da empresa, até se chegar a uma formulação final. O Código deve ter claramente explicitados os comportamentos da empresa em relação a seus empregados, o que inclui políticas de não discriminação, promoção por mérito (e não por apadrinhamento) e outras, ao lado das tradicionais restrições impostas ao corpo funcional quanto ao uso dos bens da empresa, conflitos de interesse e outros.

Depois de preparado o Código, é necessário que existam multiplicadores para apresentar e discutir seu conteúdo nas diversas áreas internas da empresa, com capacidade de dar respostas às questões mais comuns, e acesso a outros dirigentes para buscar as respostas mais complexas. Como central do programa, deve existir uma Comissão de 
Ética à qual todos tenham a possibilidade de se dirigir diretamente (de forma pessoal, por e-mail, telefone especial) ou por meio de auditores ou consultores de ética, para levantar dúvidas e questionar comportamentos da empresa ou de outros componentes do corpo funcional.

Quatro novos desafios parecem especialmente significativos para a Ética Empresarial no mundo, afetando dois deles diretamente ligados aos empregados. O primeiro é o uso das novas tecnologias de comunicação, particularmente da Internet, que cria a necessidade de novas regras. O segundo é a globalização com busca de menores custos e a generalização do capitalismo, levando ao desenvolvimento de empresas em países sem regulamentações adequadas, criando concorrência desleal às empresas organizadas e que seguem critérios éticos. O terceiro é o crescimento das organizações não-governamentais radicais, para as quais capitalismo, multinacionais e mesmo empresas são inimigos a destruir. E o quarto são as novas tecnologias em geral, que criam a necessidade da definição de parâmetros totalmente diferentes, como é o caso da biotecnologia, da nanotecnologia e outras.

\section{0 profissional de Relações Públicas e a Ética Empresarial}

Os profissionais atuantes no meio acadêmico e como consultores de Ética Organizacional têm origem variada, podendo-se citar como principais formações universitárias Filosofia, Direito, Economia e Administração, o que cria diferentes formas de abordagem. Para os formados em Filosofia, o enfoque parte dos conceitos de ética e de moral e essa base é trazida ao mundo das empresas. Já os advogados têm um forte componente jurídico na sua abordagem, enquanto administradores partem em geral dos negócios para a forma ética de realizá-los.

Embora a preparação e a implantação de códigos e programas de ética devam ser feitas usando e consultando profissionais de várias formações acadêmicas e experiências, o que se nota na prática é que os grupos responsáveis internamente pelo processo são geralmente compostos por pessoas das áreas de recursos humanos, auditoria e jurídica, com a presença eventual de diretores ou gerentes de produção ou comercialização. Nas organizações em que tive a oportunidade de trabalhar, os profissionais de Comunicação Organizacional e Relações Públicas não faziam parte das Comissões de Ética. Como responsáveis pela condução da política de relacionamento e de comunicação da empresa com os diferentes segmentos sociais, essa situação parece estranha.

Por que poucos profissionais de Relações Públicas atuam no setor? Em parte, pelo questionamento que ainda se faz à profissão e a seus objetivos. E, em alguns casos, também porque há aqueles que não acreditam em ética. Como me disse um tradicional profissional do setor: "isso de ética não existe, cada um faz as coisas como acha que pode conseguir o melhor resultado".

O questionamento à atuação de profissionais de Comunicação Organizacional e de Relações Públicas decorre não só de posturas individuais como essa, mas também 
da forma como a maior parte dos dirigentes empresariais ainda encara esses assessores, vistos como capazes de encobrir problemas, enfeitar situações ou manipular informações. Assim, Arruda (p.13) cita texto de Robert C. Salomon: "os dirigentes de empresas revoltam-se quando suas boas ações são interpretadas como meras relações públicas, como recurso de publicidade ou como forma de reduzir impostos”. Esse "meras" no texto é sintomático dessa percepção negativa.

\section{Referências}

ARRUDA, Maria Cecília. Código de ética. São Paulo: Negócio Editora, 2002.

DUMÊT, Eliana Bittencourt; TARQUíNIO, Luiz. 0 semeador de idéias. São Paulo: Editora Gente, 1999.

HUMBERG, Mario Ernesto. Ética na política e na empresa - 12 anos de reflexões. Editora CL-A, 2002.

MARCOVITCH, Jacques. Pioneiros e empreendedores. Edusp/Editora Saraiva, 2005/2007.

REVISTA EXAME. Ed. 18/08/2004, 30/03/2005, 14/02/07.

TEIXEIRA DA COSTA, Roberto. As empresas e a ética. XVIII Fórum Nacional Inae, 15/05/2006. 